\title{
Neuroimaging in Traumatic Brain Imaging
}

\author{
Bruce Lee* and Andrew Newberg ${ }^{\dagger}$ \\ *Department of Medicine, ${ }^{\dagger}$ Division of Nuclear Medicine, Department of Radiology, University of Pennsylvania Health System, \\ Philadelphia, Pennsylvania 19104
}

\begin{abstract}
Summary: Traumatic brain injury (TBI) is a common and potentially devastating clinical problem. Because prompt proper management of TBI sequelae can significantly alter the clinical course especially within $48 \mathrm{~h}$ of the injury, neuroimaging techniques have become an important part of the diagnostic work up of such patients. In the acute setting, these
\end{abstract}

imaging studies can determine the presence and extent of injury and guide surgical planning and minimally invasive interventions. Neuroimaging also can be important in the chronic therapy of TBI, identifying chronic sequelae, determining prognosis, and guiding rehabilitation. Key Words: Head injury, MRI, PET, neuroimaging, trauma, SPECT, CT.

\section{INTRODUCTION}

Traumatic brain injury (TBI) is an extremely common and potentially devastating problem. Studies have estimated that nearly 1.6 million head injuries occur in the United States each year, resulting in over 50,000 deaths and over 70,000 patients with permanent neurological deficits. ${ }^{1-3}$ TBI accounts for up to $10 \%$ of the health care budget and an estimated annual cost to society of $\$ 30$ billion. ${ }^{4}$ Because prompt proper management of TBI sequelae can significantly alter their course especially within $48 \mathrm{~h}$ of the injury, neuroimaging techniques, which can determine the presence and extent of the injury and guide surgical planning and minimally invasive interventions, play important roles in the acute therapy of TBI. ${ }^{4}$ Imaging also can be important in the chronic therapy of TBI, identifying chronic sequelae, determining prognosis, and guiding rehabilitation.

The following review will discuss the indications for imaging patients with TBI, review the roles of $x$-ray computed tomography (CT), magnetic resonance imaging (MRI), positron emission tomography (PET), singlephoton emission computed tomography (SPECT), and angiography in the management of TBI, and discuss potential future applications of these imaging modalities.

Address correspondence and reprint requests to Andrew B. Newberg, M.D., Division of Nuclear Medicine, 110 Donner Building, H.U.P., 3400 Spruce Street, Philadelphia, PA 19104. E-mail: newberg@rad.upenn.edu.
The reader is referred to a separate review on imaging of animal models of TBI published in the current volume. ${ }^{5}$

\section{INDICATIONS FOR IMAGING}

Not all head trauma patients require neuroimaging. ${ }^{6}$ Neuroimaging is, of course, costly and can consume scanner time that may be used for patients with other indications. Studies have found that less than $10 \%$ of patients that are considered to have minor head injuries have positive findings on $\mathrm{CT}$ and less than $1 \%$ require neurosurgical intervention. ${ }^{7}$ But this implies that there are still a small number of low risk patients that would benefit from neuroimaging. On the other hand, reducing the number of CT's performed on minor head injury patients even by $10 \%$ may yield more than $\$ 10$ million in savings each year. ${ }^{8,9}$

Defining minor versus major head injuries has been problematic. Certain circumstances suggest major injury and almost always merit imaging such as worsening level of consciousness, loss of consciousness for more than $5 \mathrm{~min}$, focal neurological findings, seizure, failure of the mental status to improve over time, penetrating skull injuries, signs of a basal or depressed skull fracture, or confusion or aggression on examination. ${ }^{7,10-16}$ However, there is debate over which other circumstances merit imaging. Whereas numerous criteria have been developed, including the New Orleans Criteria ${ }^{17}$ and the Canadian Head CT rules, ${ }^{18,19}$ none have been found to be completely foolproof. Even patients with the complete absence of clinical findings and high risk circumstances 
have been found to have intracerebral hemorrhage on imaging. ${ }^{20}$ Nevertheless, most investigators have focused on several criteria:

\section{Glasgow coma scale}

The Glasgow Coma Scale (GCS), which rates a patient's level of consciousness from 3 (worst) to 15 (no impairment) based on a patient's ability to open his or her eyes, talk, and move, is often used to assess injury severity. Some have suggested that any score below 15 warrants imaging, ${ }^{21,22}$ whereas other investigators have suggested that imaging should not be performed unless the score is below $13 .^{23-25}$

\section{Vomiting and headache}

Based on the New Orleans Criteria, all TBI patients with headache or vomiting should be imaged. More than two episodes of vomiting is considered by Canadian CT head rules as a high-risk factor for requiring neurosurgical intervention. ${ }^{18,19}$ However, a meta-analysis found that the presence of headache or vomiting were not predictive of intracranial hemorrhage in the pediatric population. ${ }^{26}$

\section{Amnesia}

While amnesia is included in both the New Orleans criteria ${ }^{17}$ and Canadian CT head rules, ${ }^{18,19}$ transient amnesia is common after mild head injury. Thus, longer and more severe amnesic episodes imply a greater chance of hemorrhage. A SPECT study found that amnesia lasting more than half an hour is associated with bilateral cerebral hypoperfusion. ${ }^{27}$

\section{Ethanol or drug intoxication}

The New Orleans criteria list intoxication as an indication for imaging. Series have found that up to $8 \%$ of ethanol intoxicated patients had intracerebral injury. ${ }^{6,28}$ Several mechanisms have been proposed. First of all, intoxicated patients with impaired sensoria and judgment may be more likely to suffer severe mechanisms of injuries. Secondly, chronic abuse has been found to cause brain atrophy, perhaps making the brain susceptible to insult. Finally, the presence of alcohol or other drugs of abuse may potentiate the effect of TBI on neurons and vasculature. $^{29}$

\section{Age ( $>60$ years and infants)}

According to the New Orleans criteria, all head injury patients over 60 years of age should undergo imaging, ${ }^{17}$ and according to the Canadian CT head rules, anyone over 65 years of age is at high risk for needing neurosurgical intervention. ${ }^{18,19}$ Studies have also shown a high incidence of intracranial injuries among infants who had no signs or symptoms, suggesting that imaging should be pursued more aggressively in younger children. ${ }^{30-33}$

Anticoagulation or coagulopathies. Although one study showed that patients with abnormal clotting studies were more likely to have delayed brain injury on $\mathrm{CT},{ }^{34}$ it has not been clearly established if anticoagulation or coagulopathies should affect the decision to image. ${ }^{28}$

\section{IMAGING AND ACUTE MANAGEMENT}

In the acute setting, early diagnosis and aggressive management may prevent secondary injury from the complications of brain injury. Proper management can significantly improve mortality and morbidity, while reducing hospital stay and health care costs. ${ }^{35,36}$ Imaging helps identify cerebral and cranial problems and determine their severity and operability, especially when reliable, complete neurological examinations cannot be performed. Imaging has become essential to surgical planning by providing anatomic localization and navigation information, determining extracranial landmarks to help plan the skin incision, and guiding placement of burr holes when necessary. Imaging findings also can provide important prognostic indicators, which may help decide the aggressiveness of management. ${ }^{37-39}$

Anatomical imaging with MRI is very sensitive and accurate in diagnosing cerebral pathology in TBI patients. However, conventional CT (which is more available and cost effective, requires shorter imaging time and is easier to perform on patients who are on ventilator support, in traction, or agitated) is the initial imaging modality of choice during the first $24 \mathrm{~h}$ after the injury. ${ }^{8,40-42}$ The advent of fast multidetector CT has dramatically reduced scanning time and allows for quick selective rescanning of slices that are affected by motion artifact. ${ }^{43}$ CT is also superior in evaluating bones and detecting acute subarachnoid or acute parenchymal hemorrhage. $^{44}$

Conventional CT also has its limitations. Beam-hardening effects, displacement of the CT signal near metal objects, bone, calcifications, and high concentrations of contrast, can degrade the image quality and prevent accurate assessment. CT can miss small amounts of blood that occupy widths less than a slice because of volume averaging. CT findings may lag behind actual intracranial damage, so that examinations performed within $3 \mathrm{~h}$ of trauma may underestimate injury. ${ }^{45}$ In the absence of changes in neurological status, it is still under debate whether CT scans should be repeated after a normal admission CT. ${ }^{46-48}$

Forty-eight to $72 \mathrm{~h}$ after injury, MRI is generally considered to be superior to CT. Although CT is better at detecting bony pathology and certain types of early bleeds, the ability of MRI to detect hematomas improves over time as the composition of the blood changes. The overwhelming majority of patients with mild brain injury show no abnormality on MRI. When abnormalities are present, the most common findings are hemorrhagic cortical contusions, petechia, or foci of altered signal that 


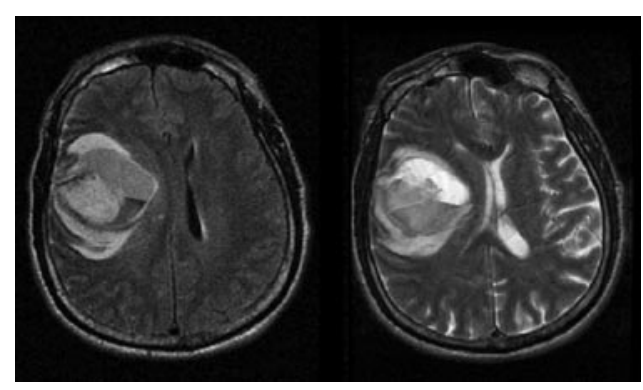

FIG. 1. MRI of 66-year-old male after a motor vehicle accident showing a large right frontal intraparenchymal hemorrhage on the FLAIR (left image) and T2 (right image) sequences. The FLARE images shows diffuse, heterogeneous increased signal intensity consistent with evolving blood products with surrounding edema in the frontal lobe.

represent white matter shear injury. When petechia resolve, they leave a permanent hemosiderin deposition on MRI. MRI is superior to CT in detecting axonal injury, small areas of contusion, and subtle neuronal damage. ${ }^{49,50}$ Studies have shown that CT missed approximately $10-20 \%$ of abnormalities seen on MRI. ${ }^{51,52}$ Moreover, MRI is better at imaging the brainstem, basal ganglia, and thalami. However, although the greater sensitivity of MRI is helpful in the subacute and chronic settings, it has not been established whether finding the additional lesions that MRI can detect would significantly change acute management of head trauma. ${ }^{44,50,53}$ Moreover, white matter changes can be found in a large percentage of healthy middle-aged individuals.

New MRI technology and acquisition sequences have improved the sensitivity of MRI. Ashikaga and colleagues $^{54}$ found fluid-attenuated inversion recovery (FLAIR) MRI, a sequence that suppresses the high signal from CSF by using a long inversion time (T1), to be more sensitive in detecting traumatic lesions and hematomas (FIG. 1). McGowan and colleagues ${ }^{55}$ demonstrated that magnetization transfer imaging (MTI), which applies radio frequency power only to the protons in the macromolecules of tissues rather than the protons in water, can add sensitivity to MRI. In a study by Lewine and colleagues ${ }^{56}$ magnetic source imaging, using a combination of MRI and magnetoencephalography, was superior to MRI alone. In separate studies, Sinson and colleagues and Cecil and colleagues ${ }^{57,58}$ found proton magnetic resonance spectroscopy to be a sensitive tool in detecting axonal injury in the corpus callosum of TBI patients. Functional MRI can demonstrate changes in regional brain activation in patients with mild TBI. ${ }^{59}$ However, all of these techniques still fell far short of $100 \%$ sensitivity in most studies reported in the literature. Moreover, they are not routinely available in many medical centers, and while the improved sensitivity may allow better prediction of outcomes, future studies will be necessary to determine how these improvements may impact acute management of TBI.
Currently, the advantages of cost and convenience for CT have limited the use of MRI in the acute management of TBI. As MRI becomes more available, newer sequences provide more information, and scanning time decreases, this may change. ${ }^{5}$ Moreover, the development of shorter MR studies using fast pulse sequences on ultra low, low, or intermediate field strength systems and nonferromagnetic monitoring and ventilation devices may allow more patients to be scanned. Additionally, investigators are using MRI to better understand the mechanisms of secondary injury in brain trauma. This may lead to preventative or preemptive treatments in the acute setting. Eventually, MRI may become a more useful tool for the early evaluation of acute brain injury.

Neither PET nor SPECT imaging is used routinely in the acute management of head trauma. Both have limited availability especially during off-hours and require a fair amount of time to complete. Because PET and SPECT imaging provide functional rather than detailed anatomic information, neither is likely to replace CT or MRI in the acute setting of head trauma. In addition, it is always important to use PET and SPECT in conjunction with anatomical imaging. Currently, SPECT and PET are more useful in guiding long-term therapy by helping establish a patient's prognosis.

\section{Hemorrhage and edema}

Hemorrhage or edema can cause mass effect, which can directly compress vascular structures, resulting in ischemia and infarct, directly impinge upon other vital structures, or herniate different parts of the brain. Therefore, hemorrhage or edema that is either worsening or already large enough to produce mass effect should be urgently evacuated. Imaging plays a crucial role in identifying, following, and governing management of these conditions. Because hemorrhages frequently progress and large contusions often develop delayed hemorrhage or edema, repeat imaging is usually indicated, especially if changes in neurological status occur. The location of the bleed helps determine the risk of mass effect and management. It also affects the relative accuracy of CT and MRI.

Brain contusions are relatively common, occurring in up to $43 \%$ of patients with blunt trauma and frequently as coup or contrecoup injuries in deceleration or acceleration trauma. ${ }^{60}$ Contusions associated with a fall, anisocoria, low GCS scores, or older patients $(>60)$ are likely to benefit from prompt neurosurgical intervention. ${ }^{61}$ On noncontrast CT, contusions appear as low attenuation if hemorrhage is absent and mixed or high attenuation if hemorrhage is present. In the acute stage, CT is more sensitive than MRI, as the clot signal can be indistinguishable from brain parenchyma on MRI. After the first few hours, the hemoglobin in the contusion loses its oxygen to become deoxyhemoglobin, which is still not 


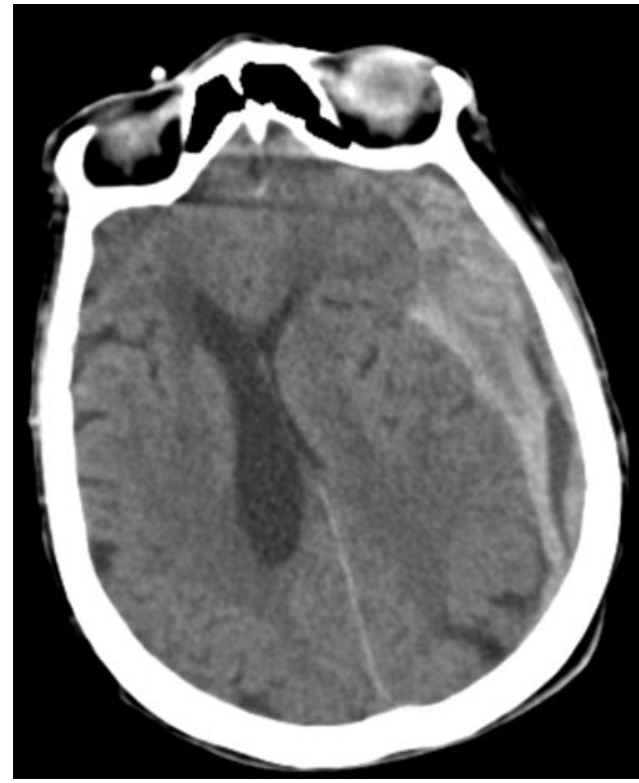

FIG. 2. CT of an 87-year-old female status post fall showing a large subdural hematoma along the left cerebral convexity with significant midline shift and effacement of the left lateral ventricle.

well visualized on T1-weighted MRI, but the concentration of red blood cells and fibrin can cause low signal on T2-weighted images. Over the next several days, as the contusion liquefies and the deoxyhemoglobin oxidizes to methemoglobin that is strongly paramagnetic, the contusion becomes more easily visualized on MRI. ${ }^{62}$

Subdural hematomas (FIG. 2) are also relatively common (10-20\% of patients with head trauma) and are associated with high mortality $(50-85 \%) .{ }^{61}$ The proximity of the skull can create beam hardening effects and also cause small hematomas to spread in a convex manner making volume averaging problems more likely. Using subdural CT windows (i.e., wider soft tissue windows) can compensate for this problem. In the subacute stage, after the initial several days, subdural hematomas approach the attenuation of normal brain parenchyma and MRI becomes more effective than CT in detection. ${ }^{63}$

Subarachnoid hemorrhages (SAH; FIG. 3) are more common in children and the elderly, who have relatively large subarachnoid spaces, and occur in up to $11 \%$ of TBI patients. It is often seen adjacent to a contusion. CT is superior to conventional MRI sequences in detecting acute SAH because the blood in acute SAH has a low hematocrit and low deoxyhemoglobin, which makes it appear similar to brain parenchyma on T1- and T2weighted spin echo images. However, FLAIR sequences may find small acute or subacute SAH missed by CT and conventional MRI. ${ }^{54,63,64}$

Epidural hematomas are relatively uncommon (1-4\% of head trauma patients) and are often associated with skull fractures. No intervention is required in stable epidural hematomas that are less than $1.5 \mathrm{~cm}$ in maximum

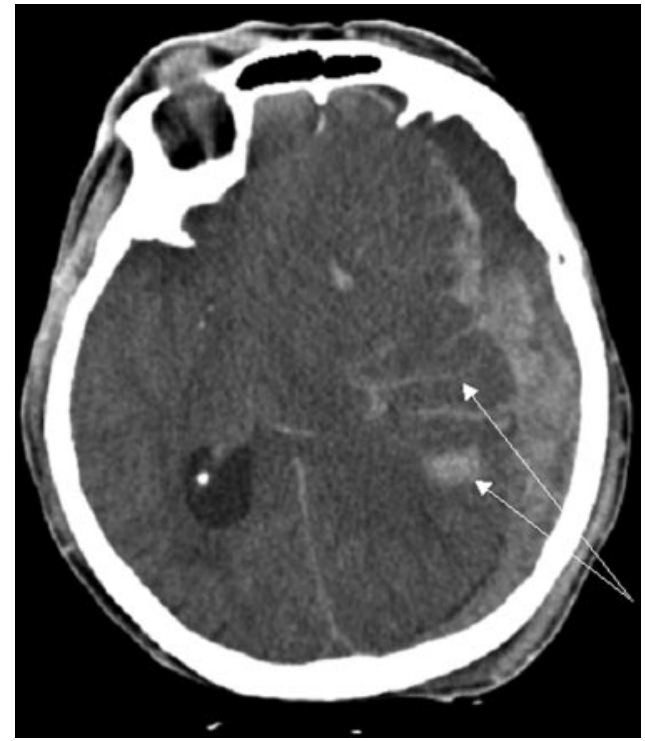

FIG. 3. CT of an 80-year-old female status post fall showing a large left subdural hematoma in addition to substantial subarachnoid hemorrhage (arrows).

width, asymptomatic, located along the convexities, and produce minimal midline shift.

Whereas intraventricular hemorrhages are also uncommon (2.8\%), they can be associated with significant morbidity and mortality. In one series, nearly half of patients with intraventricular hemorrhage developed elevated increase intracranial pressure, and $10 \%$ required ventricular drainage. On noncontrast CT, blood is of higher attenuation than the low attenuation CSF. CSF can confound interpretation on conventional MRI sequences. CSF pulsation artifacts may be misinterpreted as intraventricular hemorrhage. However, studies have suggested that FLAIR and fast spin echo FLAIR MRI may be superior to noncontrast $\mathrm{CT} .{ }^{63}$

\section{Increased intracranial pressure}

Increased increased intracranial pressure (ICP) may require ICP monitoring and treatment by osmotic agents, drainage, or hyperventilation. The absence of findings on CT certainly does not exclude elevated ICP, but the presence of any of the following should raise suspicion for intracranial hypertension: loss of gray-white junction which indicates cerebral edema, midline shift, a hematoma mass, subdural hematoma, herniation, or change in ventricular shape or size. Miller and colleagues ${ }^{65}$ found a linear association between ICP and CT findings. CT also can guide percutaneous placement of ICP monitors. ${ }^{66}$

\section{Cerebral herniation}

Cerebral herniation is a potentially devastating occurrence that can lead to compression of vital structures, vasculature, and cranial nerves. Although herniation most frequently occurs in the setting of diffuse cerebral edema, it 


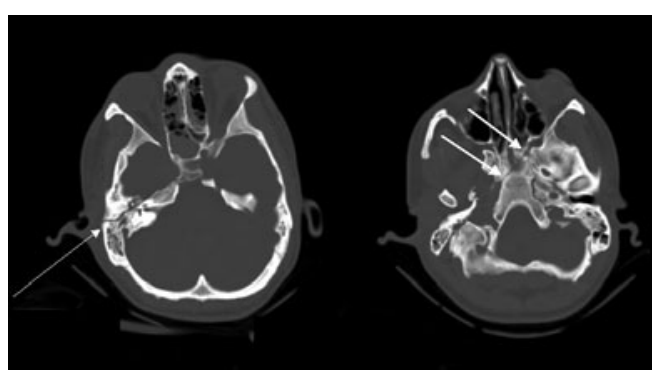

FIG. 4. CT scan of 35-year-old male with recent motor vehicle accident demonstrating longitudinal fracture of the right petrous bone (thin arrow) that extends into the skull base (thick arrow).

can occur with normal ICP when a small volume clot involves the border of two intracranial components. ${ }^{67}$

$\mathrm{CT}$ and MRI can effectively diagnose cerebral herniation. However, in some cases, MRI may be superior. The better soft tissue definition of MRI and its multiplanar imaging ability are particularly important in descending transtentorial herniation (caudal decent of the brain through the tentorial incisura). ${ }^{67-69}$ Moreover, beam hardening artifacts from the skull base and partial volume averaging effects can interfere with CT interpretation of tonsilar herniations (inferior displacement of the cerebral tonsils through the foramen magnum into the cervical spinal canal). ${ }^{67,70}$ Efforts have been made to correlate quantitative measures of herniation on imaging (i.e., the degree of shift of structures) with clinical outcomes. For example, in subfalcine herniation (midline shift or cingulated herniation), the degree of displacement of the septum pellucidum from the midline is predictive of patient prognosis. In studies of descending transtentorial herniation, the degree of vertical descent did not always correlate well with neurological signs. Because quantitative measures may be cumbersome and not be practical in clinical settings, qualitative measures may be adequate in governing management. ${ }^{67,69,71,72}$

\section{Fractures}

Depending on the location, size, and type of fracture, fractures may need to be surgically repaired to relieve or prevent CSF leakage, infection, hemorrhage, or vascular compromise. Although plain films of the skull may detect fractures, CT is the imaging modality of choice (FIG. 4). Open skull fractures depressed more then the full thickness of the skull should be surgically elevated. ${ }^{73}$ Fractures involving the paranasal sinuses, mastoid air cells, or the entire thickness of the calvarium can allow air to enter the intracranial space. Such pneumocephalus is often absorbed over time, but when persistent, raises suspicion of a CSF lead. Patients with basilar skull fractures should receive a follow-up CT scan to exclude pneumocephalus. Air appears as an area of low attenuation on CT and signal void on MRI. ${ }^{74}$

Several imaging modalities have been used to identify CSF leaks: radionuclide with 111-Indium or $99 \mathrm{~m}-\mathrm{Tc}$
DTPA, CT cisternography, and MRI using a three-dimensional-constructive interference steady-state sequence. Whereas radionuclide studies are sensitive for detecting the presence of CSF leaks, alone they are poor at providing precise anatomic localization, which is needed to guide surgical repair. Radionuclide cisternography and contrast-enhanced CT cisternography have been traditionally used. Studies have suggested that highdefinition CT alone may be adequate at detecting small fractures that are the sites of CSF leaks, while sparing patients the discomfort of an intrathecal injection and nasal pledgets. ${ }^{75,76}$

\section{Foreign bodies}

With the rising prevalence of firearms injuries, it is increasingly common to find foreign bodies in the head. Depending on their size and velocity, foreign bodies can cause damage by several mechanisms: direct laceration, shock-wave transmission (pulsations that emanate from the front of a projectile), and cavitation (the motion of the foreign body creates a suction force in its path). ${ }^{77} \mathrm{In}$ addition to finding foreign objects and determining if removal is necessary, imaging can help track the path and subsequent movement of the foreign body and anticipate the corresponding complications. Non-contrast $\mathrm{CT}$ remains the imaging modality of choice. Because metallic objects can cause significant streak artifacts, if necessary and possible, reimaging the patient while angling the gantry to avoid the metallic object can alleviate this problem. Studies on the use of MRI have been limited and have not found MRI to add information to affect acute management. Moreover, although many commercial bullets are nonferromagnetic, if there is a chance that ferromagnetic metal is present, MRI should not be used. ${ }^{77}$

\section{Vascular injury}

Trauma can disrupt arterial walls and lead to dissections, aneurysms, or fistulae. The actual incidence of vascular damage in head trauma is unclear because many lesions are asymptomatic and nowadays angiography is only performed when damage is suspected. Imaging is used to identify the presence of the vascular lesion, inform the decision to repair by determining lesion size, location, and collaterals, and guide the type and approach of the intervention.

Although contrast angiography has been the gold standard for diagnosis of vascular lesions, MRI, MRA, and CT angiography (CTA) are growing in use and capability. ${ }^{78}$ Unlike conventional angiography that only images the lumen of blood vessels, MRA and CTA can provide information about the arterial walls and MRI about the adjoining brain parenchyma. ${ }^{78}$ CTA offers better resolution and fewer flow-related artifacts than MRA. ${ }^{79-81}$

Treatment of vascular lesions can be via either open surgical or endovascular approaches. Imaging can delin- 
eate anatomy and guide open surgical approaches. ${ }^{82,83}$ Adjoining injury can block or hinder open surgical approaches. Therefore, endovascular repair, which is also less invasive, is frequently preferable. Dissections, aneurysms, and fistulae may be treated with endovascular coil embolization or stent-grafts. When the affected vessel cannot be treated, the parent artery may need to be occluded. ${ }^{84-86}$

\section{Cerebral ischemia}

Almost all of the complications of head trauma can lead ultimately to cerebral ischemia, which if untreated can result in significant morbidity and mortality. Sometimes head trauma complications are not readily identifiable, and decreased cerebral perfusion is the only sign that a correctable problem exists. Cerebral ischemia can occur in the absence of CT findings or before CT findings evolve. Because conventional CT is poor at detecting cerebral ischemia, investigators have explored the use of other modalities to detect alterations in cerebral perfusion. ${ }^{78,87}$

Perfusion CT, currently used in acute stroke and other cerebrovascular disorders, may have a role in the routine evaluation of head trauma patients. In perfusion CT, nonionic iodinated contrast material is administered intravenously, and multiple sequential CT images of the head track the flow of contrast material through the brain. ${ }^{78}$ Comparisons with stable xenon CT and PET have found that perfusion $\mathrm{CT}$ accurately assesses brain perfusion. ${ }^{88,89}$ Wintermark and colleagues ${ }^{90}$ found perfusion CT to be more sensitive $(87.5 \%$ vs $39.6 \%)$ than conventional noncontrast $\mathrm{CT}$ in detecting cerebral contusions. They also found abnormalities on perfusion CT to correlate with unfavorable clinical outcomes.

However, cerebral perfusion can be difficult to interpret in the acute phase when cerebral blood flow is uncoupled from metabolism. Injured areas may be hypo-, iso-, or hyperperfused. Hyperemia can be global, which has been linked with increased intracranial pressure, deep coma, and poor prognosis, or focal, which may or may not be associated with lower mortality. ${ }^{91}$ Furthermore, the perfusion abnormalities may result from primary vascular problems or from neuronal dysfunction and these two etiologies may be difficult to distinguish using functional imaging studies.

\section{IMAGING AND CHRONIC MANAGEMENT}

In the chronic management of head trauma, imaging has several potential roles: identifying postoperative neurophysiologic sequelae, evaluating the underlying functional abnormalities associated with late complications of head trauma, predicting long-term prognosis, guiding rehabilitation, and developing new therapies to prevent secondary injury. TBI patients can suffer from a wide variety of physical, emotional, psychological, and social difficulties that require multi-disciplinary therapy. ${ }^{92-94}$ In fact, TBI patients may be unaware that specific neurological deficits may be causing problems. ${ }^{95}$

\section{Chronic and delayed hemorrhage}

Hemorrhage can start or continue beyond the initial few days after trauma. Reaccumulation of blood may occur after evacuation, which can be best detected by CT. CT can detect other postoperative complications as well, such as subdural empyema, brain abscess, brain stem hemorrhage, cerebral edema, tension pneumocephalus, and intracerebral hemorrhage. CT is also the imaging modality of choice in revealing delayed cerebral hematoma, which should be suspected in anyone who exhibits worsening level of consciousness, new third nerve palsy, or increasing ICP, can detect delayed extraaxial hematomas, but may miss small subdural hematomas caught by MRI. ${ }^{74,96}$

As time progresses, hematomas decrease in attenuation until they becomes isodense with normal brain parenchyma 3-10 weeks after the bleed, making it difficult to detect on CT. ${ }^{97,98}$ Because old blood still emits high signal intensity on T1-weighted imaging, MRI is better at detecting chronic hemorrhage. ${ }^{99,100}$ Chronic subdural hematomas rarely spontaneously resolve, and therefore, surgical or nonsurgical (e.g., mannitol, glucocorticoids) treatment may be necessary.

\section{Prognosis and CT}

There is a significant need for objective measures to predict the clinical course of TBI patients. Clinical variables, including GCS scores, extent of amnesia, duration of ventilatory support, and duration of intensive care unit stay, have weak relationships with subsequent neuropsychiatric testing. ${ }^{101}$ Although some anatomic imaging findings such as the presence of blood or subarachnoid hemorrhage, intraventricular hemorrhage, edema, midline shift, effacement of the basal cisterns, and location of lesions have been found to be predictive of overall survival, they are not adequately predictive of functional outcome, even when clinical data are added. ${ }^{102-106}$

Ultimately, functional outcome depends on how many neurons are preserved after injury. However, the location of damage and the ability of existing neurons to reorganize their connections to recover function are also critical. Neuronal injury is caused by direct injury, compression, ischemia, and diffuse axonal injury (DAI). DAI, which occurs in up to $48 \%$ of patients with closed head injuries, is caused by the shear force generated by the rapid deceleration in motor vehicle accidents. ${ }^{60}$ The force may either tear the axons or alter axoplasmic membranes, which subsequently impairs axoplasmic transport and results in delayed damage to axons. DAI usually is diffuse and bilateral, frequently involves the lobar white matter at the gray-white matter interface and may be 
reversible. Although DAI is rarely fatal, it can result in significant neurological impairment. The number of lesions correlates with poorer outcomes, and lesions in the supratentorial white matter, corpus callosum, and corona radiate correlate with a greater likelihood that the patient will remain in a persistent vegetative state. Whereas hemorrhagic axonal injury can be seen on $\mathrm{CT}$ as multiple foci of high attenuation, nonhemorrhagic injury can be missed. In fact, CT is abnormal in less than half of all patients with DAI. ${ }^{52,107}$

\section{Prognosis and MRI}

MRI is generally more sensitive than CT for detecting neuronal damage. Patients with widespread MRI abnormalities or brain stem injuries usually show no significant neurological recovery, even when they have normal CT scans and intracranial pressures. However, aside from such obvious cases of devastating injury, a consistent relationship between MRI lesions and clinical or neuropsychological outcomes has not been demonstrated. ${ }^{108,109}$

Various newer MR technologies may provide better information for prognosis and rehabilitation guidance. Investigators have used MTI to detect white matter abnormalities in multiple sclerosis, progressive multifocal leukoencephalopathy, and Wallerian degeneration. Through MTI, a magnetization transfer ratio can be derived and quantitatively measure the structural integrity of tissues. MTI changes have been found to be more sensitive than T2-weighted MRI in detecting histologic axonal damage in animal models. ${ }^{110,111}$ Bagley and colleagues ${ }^{112}$ found associations between MTI abnormalities and neurological deficits.

Proton MR spectroscopy can detect the amount of creatinine, choline, myo-inositol, and $\mathrm{N}$-acetylaspartate (NAA) in a selected tissue volume. ${ }^{113}$ NAA, whose function has not been clearly established, has been found to be a marker for neuronal loss in a wide variety of conditions including spinal cord injury, amyotrophic lateral sclerosis, Parkinson disease, Huntington disease, ischemic stroke, progressive multifocal leukoencephalopathy, epilepsy, and multiple sclerosis, as reviewed separately in the current volume. ${ }^{5,113}$ Animal models of brain injury have shown NAA levels to decrease within hours after injury. ${ }^{5,114,115}$ Several investigators have found lower NAA to creatinine ratios as measured by MR spectroscopy to correlate with poorer clinical outcomes. ${ }^{58,116,117}$ Finally, functional MRI studies by McAllister and colleagues ${ }^{59}$ found persistent changes in the brain activation patterns of mild TBI patients compared with controls when given various working memory tasks.

\section{Prognosis and SPECT}

SPECT can detect abnormalities in cerebral blood flow $(\mathrm{CBF})$ as reviewed separately in the current volume. ${ }^{118}$ Not all alterations in cerebral blood flow are associated

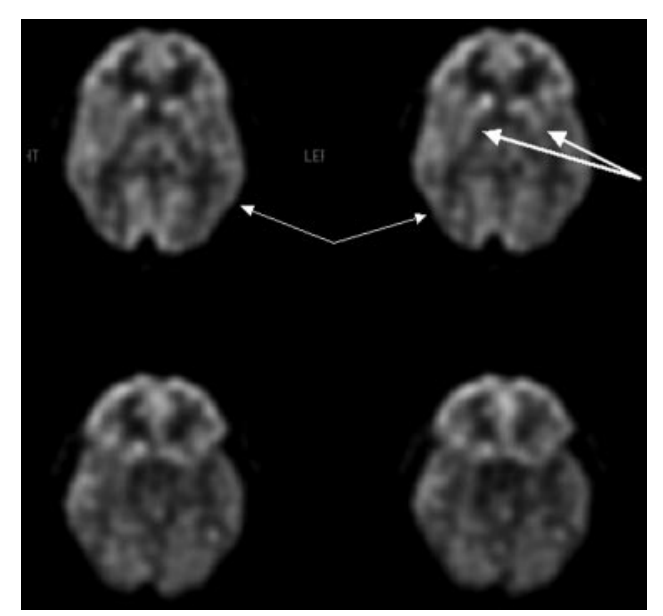

FIG. 5. FDG-PET scan of 33-year-old male status post motor vehicle accident demonstrates hypometabolism affecting the temporo-parietal and occipital (thin arrows) regions as well as the caudate and putamen (thick arrows), which are findings suggesting diffuse axonal injury.

with lesions on CT and vice versa. ${ }^{119,120}$ In general, SPECT is more sensitive than CT in detecting lesions in TBI patients. ${ }^{121,122}$ However, it is not always clear whether the abnormalities observed on SPECT correspond to direct or indirect injury, or possibly abnormalities from prior trauma or other neuropsychiatric conditions. CBF abnormalities are commonly seen in mild TBI patients with chronic symptoms, even if no structural damage is apparent. ${ }^{123}$ Often the size of the lesion on SPECT exceeds the size of the lesion on CT or MRI.

SPECT appears to be better than CT or MRI in determining long-term prognosis. ${ }^{122,124} \mathrm{~A}$ negative initial SPECT scan after trauma seems to strongly predict a favorable clinical outcome. ${ }^{125} \mathrm{~A}$ worse prognosis is associated with larger lesions, multiple defects, and lesions in the brainstem, temporal lobes, parietal lobes, or basal ganglia. Abnormal SPECT can be predictive of neuropsychological deficits. ${ }^{126}$ Studies have found that decreased blood flow to various parts of the brain correlate with various types of behavior: the frontal lobes with disinhibitive behavior, the left cerebral hemisphere with increased social isolation, and the right hemispheric areas with increased aggressive behavior. ${ }^{127}$ Deficits in frontal lobe and thalamic perfusion have been linked to impairments in executive functioning. ${ }^{128}$ However, no consistent correlation between SPECT abnormalities and neuropsychological test scores has been established. ${ }^{129}$ Because MRI detects lesions missed by SPECT and vice versa, a combination of MR and SPECT may be even better for determining prognosis. ${ }^{130}$

\section{Prognosis and PET}

As reviewed separately in the current volume, ${ }^{131}$ PET measures the cerebral metabolism of various substrates, most commonly fluorodeoxyglucose in the measurement of glucose metabolism, which should correspond to neu- 


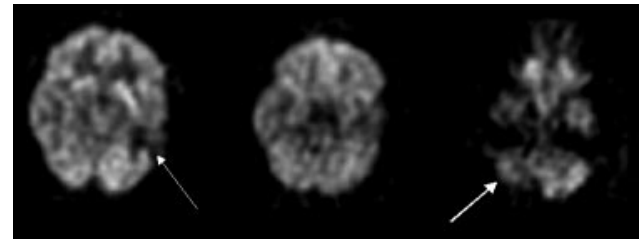

FIG. 6. FDG-PET scan of a 38-year-old male with head injury 15 years ago with encephalomalacia in the left temporal lobe demonstrates marked hypometabolism in the left temporal lobe (thin arrow) and right cerebellar hypometabolism (thick arrow) consistent with crossed cerebellar diaschisis.

ronal viability. PET can also be used to diagnose patients with DAI to determine the extent of damage and prognosis (FIG. 5). PET studies may help delineate reversible and irreversible lesions to direct therapeutic interventions toward preventing further damage. The major limitation of PET imaging is that it cannot distinguish between functional abnormalities associated and not associated with structural damage. In general, studies have found that cerebral dysfunction can extend far beyond the boundary of anatomical lesions and may even appear in locations remote from the trauma. Alavi and colleagues $^{132}$ showed that approximately $33 \%$ of anatomical lesions were associated with larger and more widespread metabolic abnormalities. As much as $42 \%$ of PET abnormalities were not associated with any anatomical lesions observed on anatomical images. The metabolic effects of cortical contusions, intracranial hematoma, and resultant encephalomalacia are primarily confined to the site of injury (FIG. 6), whereas those of subdural and epidural hematomas often are widespread and may even affect the contralateral hemisphere. DAI results in diffuse hypometabolism. ${ }^{132,133}$

Alavi and colleagues ${ }^{132}$ found that GCS scores of 13 and lower were associated with whole brain hypometabolism on ${ }^{18}$ F-fluorodeoxyglucose (FDG)-PET. Studies have shown that PET can uncover areas of cerebral hypometabolism that are associated with neurological and behavioral dysfunction but not detected on CT, MRI, or EEG (FIGS. 7 and 8). ${ }^{134,135}$ Moreover, some of these areas eventually develop structural abnormalities such as encephalomalacia and atrophy on CT. Separate studies by Gross ${ }^{136}$ and Ruff ${ }^{137}$ found PET hypometabolism to significantly correlate with overall clinical complaints and overall neuropsychological test results. However,

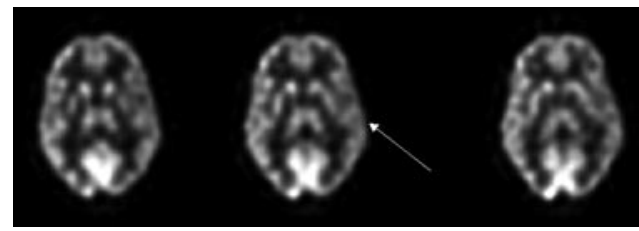

FIG. 7. FDG-PET scan of a 43-year-old female with head injury 2 years ago now with cognitive and memory dysfunction as well as language problems demonstrates hypometabolism in the entire left hemisphere (arrow) related to the head trauma.

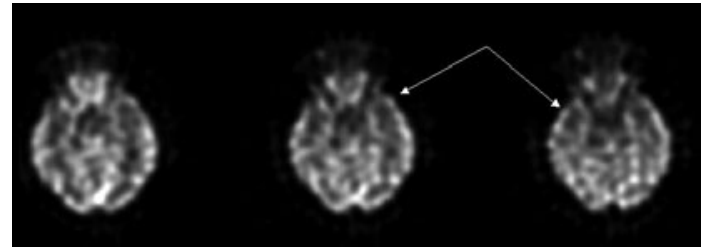

FIG. 8. FDG-PET scan of a 49-year-old female with MVA 6 years ago and persistent headache and memory problems with bilateral decreased temporal lobe metabolism (arrows).

PET imaging can also uncover other potentially confounding neuropsychiatric conditions such as depression or drug induced effects (FIG. 9). Furthermore, several studies have shown that the glucose metabolic abnormalities observed on PET are associated with a number of possible mechanisms and therefore may not provide sufficient data to assess global function and level of consciousness in head injury patients. ${ }^{138,139}$

\section{Imaging and new therapies}

Imaging is playing a crucial role in defining the mechanisms of secondary injury in TBI and, in turn, potentially identifying targets of new therapies. ${ }^{140} \mathrm{TBI}$ is found to initiate an inflammatory cascade that results in the release of amino acids, such as glutamate and aspartate, and free radicals, that may lead to further tissue damage. ${ }^{141}$ Other potential culprits include nitrous oxide, endogenous opioid peptides such as naloxone, catecholamines, acetylcholine, thyrotropin-releasing hormone (TRH), lactate, and adenosine. ${ }^{142,143}$ Cytokines such as tumor necrosis factor (TNF) and interleukins 1,6, and 8, also have found to increase following TBI. ${ }^{144,145}$ PET, functional MRI, MR spectroscopy, and SPECT, have been and will continue to be crucial in identifying the concentrations and locations of these various molecules in animal and human brains following injury. In animal models, imaging has been used to determine the effectiveness of glutamate and $\mathrm{N}$-methyl-D-aspartate receptor blockers and antioxidants on TBI. ${ }^{146,147}$ Ischemia and reperfusion injury are thought to play important roles, and imaging has been important in understanding perfusion changes after TBI as well helping develop therapies to alter perfusion. ${ }^{148,149}$ Using PET to measure $\mathrm{CBF}$, oxygen metabolism, and the oxygen extraction

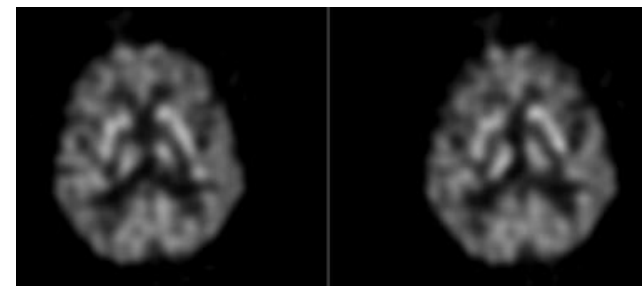

FIG. 9. FDG-PET scan of a 69-year-old boxer with visual and memory problems evaluated for dementia pugilistica. The findings demonstrate moderate global cortical hypometabolism and preservation of subcortical and occipital structures most consistent with depression, not DAI. 
fraction $(\mathrm{OEF})$ in severe brain injury, Yamaki and colleagues ${ }^{150}$ found that long-lasting anaerobic glycolysis with high OEF and a relatively low ratio of oxygen metabolism to glucose metabolism predicted poor outcomes. SPECT and PET imaging have been used to measure improvements in cerebral blood flow associated with hyperbaric oxygen therapy ${ }^{151}$ and hyperventilation ${ }^{152}$ therapy in TBI patients.

\section{CONCLUSIONS}

In the future, the already significant role of imaging in guiding therapy may grow. Technological improvements continue to reduce scanning time and improve resolution. New methods are being developed to quantify damage on images and perhaps improve predictive power. A growing number of minimally invasive, image-guided techniques are replacing open surgical techniques. Imaging is increasingly vital to the development of new therapies and may be used to measure patient response to these therapies. Imaging has and will continue to influence therapy and may improve outcomes for what is clearly a significant health care problem.

\section{REFERENCES}

1. Sosin DM, Sniezek JE, Waxweiler RJ. Trends in death associated with traumatic brain injury, 1979 through 1992 . Success and failure. JAMA 273:1778-1780, 1995.

2. Sosin DM, Sniezek JE, Thurman DJ. Incidence of mild and moderate brain injury in the United States, 1991. Brain Inj 10: 47-54, 1996.

3. Traumatic brain injury-Colorado, Missouri, Oklahoma, and Utah, 1990-1993. MMWR Morb Mortal Wkly Rep 46:8-11, 1997.

4. Hoyt DB, Holcomb J, Abraham E, Atkins J, Sopko G. Working Group on Trauma Research Program Summary Report: National Heart Lung Blood Institute (NHLBI), National Institute of General Medical Sciences (NIGMS), and National Institute of Neurological Disorders and Stroke (NINDS) of the National Institutes of Health (NIH), and the Department of Defense (DOD). J Trauma 57:410-415, 2004.

5. Pirko I, Fricke ST, Johnson AJ, Rodriguez M, Macura SI. Magnetic resonance imaging, microscopy, and spectroscopy of the central nervous system in experimental animals. NeuroRx 2:250264, 2005.

6. Nagy KK, Joseph KT, Krosner SM, Roberts RR, Leslie CL, Dufty K, et al. The utility of head computed tomography after minimal head injury. J Trauma 46:268-270, 1999.

7. Jeret JS, Mandell M, Anziska B, Lipitz M, Vilceus AP, Ware JA, et al. Clinical predictors of abnormality disclosed by computed tomography after mild head trauma. Neurosurgery 32:9-15, 1993.

8. Miller EC, Holmes JF, Derlet RW. Utilizing clinical factors to reduce head CT scan ordering for minor head trauma patients. J Emerg Med 15:453-457, 1997.

9. Reinus WR, Wippold FJ 2nd, Erickson KK. Practical selection criteria for noncontrast cranial computed tomography in patients with head trauma. Ann Emerg Med 22:1148-1155, 1993.

10. Moran SG, McCarthy MC, Uddin DE, Poelstra RJ. Predictors of positive CT scans in the trauma patient with minor head injury. Am Surg 60:533-535, 1994.

11. Duus BR, Lind B, Christensen H, Nielsen OA. The role of neuroimaging in the initial management of patients with minor head injury. Ann Emerg Med 23:1279-1283, 1994.
12. Bock K, Duus JO, Hindsgaul O, Lindh I. Analysis of conformationally restricted models for the (1-6)-branch of asparaginelinked oligosaccharides by n.m.r.-spectroscopy and HSEA calculation. Carbohydr Res 228:1-20, 1992.

13. Birn B, Gadegard E, Lind PO, Bergsoe K, Metze E, Birn H, et al. [Social and behavioral subjects in dental care training]. Tandlaegebladet 80:555-559, 1976.

14. Ingebrigtsen T, Romner B. Management of minor head injuries in hospitals in Norway. Acta Neurol Scand 95:51-55, 1997.

15. Ingebrigtsen T, Romner B. Routine early CT-scan is cost saving after minor head injury. Acta Neurol Scand 93:207-210, 1996.

16. Schunk JE, Rodgerson JD, Woodward GA. The utility of head computed tomographic scanning in pediatric patients with normal neurologic examination in the emergency department. Pediatr Emerg Care 12:160-165, 1996.

17. Haydel MJ, Preston CA, Mills TJ, Luber S, Blaudeau E, DeBlieux PM. Indications for computed tomography in patients with minor head injury. N Engl J Med 343:100-105, 2000.

18. Stiell IG, Lesiuk H, Wells GA, Coyle D, McKnight RD, Brison R, et al. Canadian CT head rule study for patients with minor head injury: methodology for phase II (validation and economic analysis). Ann Emerg Med 38:317-322, 2001.

19. Stiell IG, Lesiuk H, Wells GA, McKnight RD, Brison R, Clement C, et al. The Canadian CT Head Rule Study for patients with minor head injury: rationale, objectives, and methodology for phase I (derivation). Ann Emerg Med 38:160-169, 2001.

20. Quayle KS, Jaffe DM, Kuppermann N, Kaufman BA, Lee BC, Park TS, et al. Diagnostic testing for acute head injury in children: when are head computed tomography and skull radiographs indicated? Pediatrics 99:E11, 1997.

21. Ingebrigtsen T, Romner B, Kock-Jensen C. Scandinavian guidelines for initial management of minimal, mild, and moderate head injuries. The Scandinavian Neurotrauma Committee. I Trauma 48:760-766, 2000.

22. Stein SC, Ross SE. The value of computed tomographic scans in patients with low-risk head injuries. Neurosurgery 26:638-640, 1990.

23. Feuerman T, Wackym PA, Gade GF, Becker DP. Value of skull radiography, head computed tomographic scanning, and admission for observation in cases of minor head injury. Neurosurgery 22:449-453, 1988

24. Stein SC, O'Malley KF, Ross SE. Is routine computed tomography scanning too expensive for mild head injury? Ann Emerg Med 20:1286-1289, 1991.

25. Shackford SR, Wald SL, Ross SE, Cogbill TH, Hoyt DB, Morris JA, et al. The clinical utility of computed tomographic scanning and neurologic examination in the management of patients with minor head injuries. J Trauma 33:385-394, 1992.

26. Dunning J, Batchelor J, Stratford-Smith P, Teece S, Browne J, Sharpin C, et al. A meta-analysis of variables that predict significant intracranial injury in minor head trauma. Arch Dis Child 89:653-659, 2004.

27. Lorberboym M, Lampl Y, Gerzon I, Sadeh M. Brain SPECT evaluation of amnestic ED patients after mild head trauma. Am J Emerg Med 20:310-313, 2002.

28. Cook LS, Levitt MA, Simon B, Williams VL. Identification of ethanol-intoxicated patients with minor head trauma requiring computed tomography scans. Acad Emerg Med 1:227-234, 1994

29. Wilde EA, Bigler ED, Gandhi PV, Lowry CM, Blatter DD, Brooks J, et al. Alcohol abuse and traumatic brain injury: quantitative magnetic resonance imaging and neuropsychological outcome. J Neurotrauma 21:137-147, 2004.

30. Schutzman SA, Greenes DS. Pediatric minor head trauma. Ann Emerg Med 37:65-74, 2001.

31. Greenes DS, Schutzman SA. Occult intracranial injury in infants. Ann Emerg Med 32:680-686, 1998.

32. Greenes DS, Schutzman SA. Clinical indicators of intracranial injury in head-injured infants. Pediatrics 104:861-867, 1999.

33. Kraus JF, Fife D, Cox P, Ramstein K, Conroy C. Incidence, severity, and external causes of pediatric brain injury. Am J Dis Child 140:687-693, 1986.

34. Reinus WR, Zwemer FL Jr. Clinical prediction of emergency 
cranial computed tomography results. Ann Emerg Med 23:12711278, 1994.

35. Watts DD, Hanfling D, Waller MA, Gilmore C, Fakhry SM, Trask AL. An evaluation of the use of guidelines in prehospital management of brain injury. Prehosp Emerg Care 8:254-261, 2004.

36. Fakhry SM, Trask AL, Waller MA, Watts DD. Management of brain-injured patients by an evidence-based medicine protocol improves outcomes and decreases hospital charges. J Trauma 56:492-499, 2004.

37. Chesnut RM. Implications of the guidelines for the management of severe head injury for the practicing neurosurgeon. Surg Neurol 50:187-193, 1998.

38. Bullock R, Chesnut RM, Clifton G, Ghajar J, Marion DW, Narayan RK, et al. Guidelines for the management of severe head injury. Brain Trauma Foundation. Eur J Emerg Med 3:109-127, 1996.

39. Chesnut RM, Marshall LF, Klauber MR, Blunt BA, Baldwin N, Eisenberg HM, et al. The role of secondary brain injury in determining outcome from severe head injury. J Trauma 34:216222, 1993.

40. Kelly AB, Zimmerman RD, Snow RB, Gandy SE, Heier LA, Deck MD. Head trauma: comparison of MR and CT-experience in 100 patients. AJNR Am J Neuroradiol 9:699-708, 1988.

41. Ahmadi J, Destian S. Head trauma. Top Magn Reson Imaging 2:17-24, 1989.

42. Glauser J. Head injury: which patients need imaging? Which test is best? Cleve Clin J Med 71:353-357, 2004.

43. Jones TR, Kaplan RT, Lane B, Atlas SW, Rubin GD. Singleversus multi-detector row $\mathrm{CT}$ of the brain: quality assessment. Radiology 219:750-755, 2001.

44. Yealy DM, Hogan DE. Imaging after head trauma. Who needs what? Emerg Med Clin North Am 9:707-717, 1991.

45. Servadei F, Nasi MT, Giuliani G, Cremonini AM, Cenni P, Zappi $\mathrm{D}$, et al. CT prognostic factors in acute subdural haematomas: the value of the 'worst' CT scan. Br J Neurosurg 14:110-116, 2000.

46. Fainardi E, Chieregato A, Antonelli V, Fagioli L, Servadei F. Time course of CT evolution in traumatic subarachnoid haemorrhage: a study of 141 patients. Acta Neurochir (Wien) 146:257263,2004

47. Sifri ZC, Livingston DH, Lavery RF, Homnick AT, Mosenthal AC, Mohr AM, et al. Value of repeat cranial computed axial tomography scanning in patients with minimal head injury. Am J Surg 187:338-342, 2004.

48. Figg RE, Burry TS, Vander Kolk WE. Clinical efficacy of serial computed tomographic scanning in severe closed head injury patients. J Trauma 55:1061-1064, 2003.

49. Levin HS, Amparo E, Eisenberg HM, Williams DH, High WM Jr, McArdle CB, et al. Magnetic resonance imaging and computerized tomography in relation to the neurobehavioral sequelae of mild and moderate head injuries. J Neurosurg 66:706-713, 1987.

50. Ogawa T, Sekino H, Uzura M, Sakamoto T, Taguchi Y, Yamaguchi Y, et al. Comparative study of magnetic resonance and CT scan imaging in cases of severe head injury. Acta Neurochir Suppl (Wien) 55:8-10, 1992.

51. Doezema D, King JN, Tandberg D, Espinosa MC, Orrison WW. Magnetic resonance imaging in minor head injury. Ann Emerg Med 20:1281-1285, 1991.

52. Mittl RL, Grossman RI, Hiehle JF, Hurst RW, Kauder DR, Gennarelli TA, et al. Prevalence of MR evidence of diffuse axonal injury in patients with mild head injury and normal head CT findings. AJNR Am J Neuroradiol 15:1583-1589, 1994.

53. Kent DL, Haynor DR, Longstreth WT Jr, Larson EB. The clinical efficacy of magnetic resonance imaging in neuroimaging. Ann Intern Med 120:856-871, 1994.

54. Ashikaga R, Araki Y, Ishida O. MRI of head injury using FLAIR. Neuroradiology 39:239-242, 1997.

55. McGowan JC, Yang JH, Plotkin RC, Grossman RI, Umile EM, Cecil KM, et al. Magnetization transfer imaging in the detection of injury associated with mild head trauma. AJNR Am J Neuroradiol 21:875-880, 2000.

56. Lewine JD, Davis JT, Sloan JH, Kodituwakku PW, Orrison WW Jr. Neuromagnetic assessment of pathophysiologic brain activity induced by minor head trauma. AJNR Am J Neuroradiol 20:857866, 1999.

57. Cecil KM, Hills EC, Sandel ME, Smith DH, McIntosh TK, Mannon LJ, et al. Proton magnetic resonance spectroscopy for detection of axonal injury in the splenium of the corpus callosum of brain-injured patients. J Neurosurg 88:795-801, 1998.

58. Sinson G, Bagley LJ, Cecil KM, Torchia M, McGowan JC, Lenkinski RE, et al. Magnetization transfer imaging and proton MR spectroscopy in the evaluation of axonal injury: correlation with clinical outcome after traumatic brain injury. AJNR Am J Neuroradiol 22:143-151, 2001.

59. McAllister TW, Saykin AJ, Flashman LA, Sparling MB, Johnson $\mathrm{SC}$, Guerin SJ, et al. Brain activation during working memory 1 month after mild traumatic brain injury: a functional MRI study. Neurology 53:1300-1308, 1999.

60. Deleted in proof.

61. Gutman MB, Moulton RJ, Sullivan I, Hotz G, Tucker WS, Muller PJ. Risk factors predicting operable intracranial hematomas in head injury. J Neurosurg 77:9-14, 1992.

62. Bradley WG. MR appearance of hemorrhage in the brain. Radiology 189:15-26, 1993.

63. Bakshi R, Kamran S, Kinkel PR, Bates VE, Mechtler LL, Janardhan $\mathrm{V}$, et al. Fluid-attenuated inversion-recovery MR findings in acute and subacute cerebral intraventricular hemorrhage. AJNR Am J Neuroradiol 20:629-636, 1999.

64. Bakshi R. Diffusion-weighted MRI as an evolving standard of care in acute stroke. Neurology 55:1595, 2000.

65. Miller MT, Pasquale M, Kurek S, White J, Martin P, Bannon K, et al. Initial head computed tomographic scan characteristics have a linear relationship with initial intracranial pressure after trauma. J Trauma 56:967-972, 2004.

66. Krotz M, Linsenmaier U, Kanz KG, Pfeifer KJ, Mutschler W, Reiser M. Evaluation of minimally invasive percutaneous CTcontrolled ventriculostomy in patients with severe head trauma. Eur Radiol 14:227-233, 2004.

67. Johnson PL, Eckard DA, Chason DP, Brecheisen MA, Batnitzky S. Imaging of acquired cerebral herniations. Neuroimaging Clin N Am 12:217-228, 2002.

68. Hahn FJ, Gurney J. CT signs of central descending transtentorial herniation. AJNR Am J Neuroradiol 6:844-845, 1985.

69. Feldmann E, Gandy SE, Becker R, Zimmerman R, Thaler HT, Posner JB, et al. MRI demonstrates descending transtentorial herniation. Neurology 38:697-701, 1988.

70. Ishikawa M, Kikuchi H, Fujisawa I, Yonekawa Y. Tonsillar herniation on magnetic resonance imaging. Neurosurgery 22:77-81, 1988.

71. Reich JB, Sierra J, Camp W, Zanzonico P, Deck MD, Plum F. Magnetic resonance imaging measurements and clinical changes accompanying transtentorial and foramen magnum brain herniation. Ann Neurol 33:159-170, 1993.

72. Ropper AH. A preliminary MRI study of the geometry of brain displacement and level of consciousness with acute intracranial masses. Neurology 39:622-627, 1989.

73. Gruen P. Surgical management of head trauma. Neuroimaging Clin N Am 12:339-343, 2002.

74. Zee CS, Hovanessian A, Go JL, Kim PE. Imaging of sequelae of head trauma. Neuroimaging Clin N Am 12:325-338, 2002.

75. Stone JA, Castillo M, Neelon B, Mukherji SK. Evaluation of CSF leaks: high-resolution CT compared with contrast-enhanced CT and radionuclide cisternography. AJNR Am J Neuroradiol 20: 706-712, 1999.

76. Lloyd MN, Kimber PM, Burrows EH. Post-traumatic cerebrospinal fluid rhinorrhoea: modern high-definition computed tomography is all that is required for the effective demonstration of the site of leakage. Clin Radiol 49:100-103, 1994.

77. Kim PE, Go JL, Zee CS. Radiographic assessment of cranial gunshot wounds. Neuroimaging Clin N Am 12:229-248, 2002.

78. Sá de Camargo EC, Koroshetz WJ. Neuroimaging of ischemia and infarction. NeuroRx 2:265-276, 2005.

79. Biffl WL, Ray CE Jr, Moore EE, Mestek M, Johnson JL, Burch JM. Noninvasive diagnosis of blunt cerebrovascular injuries: a preliminary report. J Trauma 53:850-856, 2002. 
80. Munera F, Soto JA, Palacio D, Velez SM, Medina E. Diagnosis of arterial injuries caused by penetrating trauma to the neck: comparison of helical CT angiography and conventional angiography. Radiology 216:356-362, 2000.

81. Rogers FB, Baker EF, Osler TM, Shackford SR, Wald SL, Vieco P. Computed tomographic angiography as a screening modality for blunt cervical arterial injuries: preliminary results. J Trauma 46:380-385, 1999.

82. Wellwood J, Alcantara A, Michael DB. Neurotrauma: the role of CT angiogram. Neurol Res 24:S13-S16, 2002.

83. Guyot LL, Kazmierczak CD, Diaz FG. Vascular injury in neurotrauma. Neurol Res 23:291-296, 2001.

84. Larsen DW. Traumatic vascular injuries and their management. Neuroimaging Clin N Am 12:249-269, 2002.

85. Lempert TE, Malek AM, Halbach VV, Phatouros CC, Meyers PM, Dowd CF, et al. Endovascular treatment of ruptured posterior circulation cerebral aneurysms. Clinical and angiographic outcomes. Stroke 31:100-110, 2000.

86. Redekop G, Marotta T, Weill A. Treatment of traumatic aneurysms and arteriovenous fistulas of the skull base by using endovascular stents. J Neurosurg 95:412-419, 2001.

87. Steiner LA, Czosnyka M. Should we measure cerebral blood flow in head-injured patients? Br J Neurosurg 16:429-439, 2002.

88. Kudo K, Terae S, Katoh C, Oka M, Shiga T, Tamaki N, et al. Quantitative cerebral blood flow measurement with dynamic perfusion CT using the vascular-pixel elimination method: comparison with $\mathrm{H} 2(15) \mathrm{O}$ positron emission tomography. AJNR Am J Neuroradiol 24:419-426, 2003.

89. Furukawa M, Kashiwagi S, Matsunaga N, Suzuki M, Kishimoto K, Shirao S. Evaluation of cerebral perfusion parameters measured by perfusion CT in chronic cerebral ischemia: comparison with xenon CT. J Comput Assist Tomogr 26:272-278, 2002.

90. Wintermark M, van Melle G, Schnyder P, Revelly JP, Porchet F, Regli L, et al. Admission perfusion CT: prognostic value in patients with severe head trauma. Radiology 232:211-220, 2004.

91. Sakas DE, Bullock MR, Patterson J, Hadley D, Wyper DJ, Teasdale GM. Focal cerebral hyperemia after focal head injury in humans: a benign phenomenon? J Neurosurg 83:277-284, 1995.

92. Hoofien D, Gilboa A, Vakil E, Donovick PJ. Traumatic brain injury (TBI) 10-20 years later: a comprehensive outcome study of psychiatric symptomatology, cognitive abilities and psychosocial functioning. Brain Inj 15:189-209, 2001.

93. Hoofien D, Vakil E, Gilboa A, Donovick PJ, Barak O. Comparison of the predictive power of socio-economic variables, severity of injury and age on long-term outcome of traumatic brain injury: sample-specific variables versus factors as predictors. Brain Inj 16:9-27, 2002.

94. Corrigan JD, Whiteneck G, Mellick D. Perceived needs following traumatic brain injury. J Head Trauma Rehabil 19:205-216, 2004.

95. Hoofien D, Gilboa A, Vakil E, Barak O. Unawareness of cognitive deficits and daily functioning among persons with traumatic brain injuries. J Clin Exp Neuropsychol 26:278-290, 2004.

96. Gentleman D, Nath F, Macpherson P. Diagnosis and management of delayed traumatic intracerebral haematomas. Br J Neurosurg 3:367-372, 1989.

97. Kostanian V, Choi JC, Liker MA, Go JL, Zee CS. Computed tomographic characteristics of chronic subdural hematomas. Neurosurg Clin N Am 11:479-489, 2000.

98. Lee KS, Bae WK, Bae HG, Doh JW, Yun IG. The computed tomographic attenuation and the age of subdural hematomas. $J$ Korean Med Sci 12:353-359, 1997.

99. Ebisu T, Naruse S, Horikawa Y, Tanaka C, Higuchi T. Nonacute subdural hematoma: fundamental interpretation of MR images based on biochemical and in vitro MR analysis. Radiology 171: 449-453, 1989.

100. Wilms G, Marchal G, Geusens E, Raaijmakers C, Van Calenbergh F, Goffin J, et al. Isodense subdural haematomas on CT: MRI findings. Neuroradiology 34:497-499, 1992.

101. Demetriades D, Kuncir E, Murray J, Velmahos GC, Rhee P, Chan L. Mortal prediction of head Abbreviated Injury Score and Glasgow Coma Scale: analysis of 7,764 head injuries. J Am Coll Surg 199:216-222, 2004.
102. Azian AA, Nurulazman AA, Shuaib L, Mahayidin M, Ariff AR, Naing NN, et al. Computed tomography of the brain in predicting outcome of traumatic intracranial haemorrhage in Malaysian patients. Acta Neurochir (Wien) 143:711-720, 2001.

103. Ono J, Yamaura A, Kubota M, Okimura Y, Isobe K. Outcome prediction in severe head injury: analyses of clinical prognostic factors. J Clin Neurosci 8:120-123, 2001.

104. Marshall LF, Marshall SB, Klauber MR, Van Berkum Clark M, Eisenberg H, Jane JA, et al. The diagnosis of head injury requires a classification based on computed axial tomography. J Neurotrauma 9:S287-292, 1992.

105. Aldrich EF, Eisenberg HM, Saydjari C, Foulkes MA, Jane JA, Marshall LF, et al. Predictors of mortality in severely headinjured patients with civilian gunshot wounds: a report from the NIH Traumatic Coma Data Bank. Surg Neurol 38:418-423, 1992.

106. Wardlaw JM, Easton VJ, Statham P. Which CT features help predict outcome after head injury? J Neurol Neurosurg Psychiatry 72:188-192, 2002.

107. Hammoud DA, Wasserman BA. Diffuse axonal injuries: pathophysiology and imaging. Neuroimaging Clin N Am 12:205-216, 2002.

108. Levin HS, Amparo EG, Eisenberg HM, Miner ME, High WM Jr, Ewing-Cobbs L, et al. Magnetic resonance imaging after closed head injury in children. Neurosurgery 24:223-227, 1989.

109. Wilson JT, Wiedmann KD, Hadley DM, Condon B, Teasdale G, Brooks DN. Early and late magnetic resonance imaging and neuropsychological outcome after head injury. J Neurol Neurosurg Psychiatry 51:391-396, 1988.

110. Lexa FJ, Grossman RI, Rosenquist AC. Dyke Award paper. MR of wallerian degeneration in the feline visual system: characterization by magnetization transfer rate with histopathologic correlation. AJNR Am J Neuroradiol 15:201-212, 1994.

111. Kimura H, Meaney DF, McGowan JC, Grossman RI, Lenkinski RE, Ross DT, et al. Magnetization transfer imaging of diffuse axonal injury following experimental brain injury in the pig: characterization by magnetization transfer ratio with histopathologic correlation. J Comput Assist Tomogr 20:540-546, 1996.

112. Bagley LJ, McGowan JC, Grossman RI, Sinson G, Kotapka M, Lexa FJ, et al. Magnetization transfer imaging of traumatic brain injury. J Magn Reson Imaging 11:1-8, 2000.

113. Lin A, Ross BD, Harris K, Wong W. Efficacy of proton magnetic resonance spectroscopy in neurological diagnosis and neurotherapeutic decision making. NeuroRx 2:197-214, 2005.

114. Rubin Y, Cecil K, Wehrli S, McIntosh TK, Lenkinski RE, Smith DH. High-resolution 1H NMR spectroscopy following experimental brain trauma. J Neurotrauma 14:441-449, 1997.

115. Cecil KM, Lenkinski RE, Meaney DF, McIntosh TK, Smith DH. High-field proton magnetic resonance spectroscopy of a swine model for axonal injury. J Neurochem 70:2038-2044, 1998.

116. Choe BY, Suh TS, Choi KH, Shinn KS, Park CK, Kang JK. Neuronal dysfunction in patients with closed head injury evaluated by in vivo $1 \mathrm{H}$ magnetic resonance spectroscopy. Invest Radiol 30:502-506, 1995.

117. Holshouser BA, Ashwal S, Luh GY, Shu S, Kahlon S, Auld KL, et al. Proton MR spectroscopy after acute central nervous system injury: outcome prediction in neonates, infants, and children. Radiology 202:487-496, 1997.

118. McAllister TW, Sparling MB, Flashman LA, Saykin AJ. Neuroimaging findings in mild traumatic brain injury. J Clin Exp Neuropsychol 23:775-791, 2001.

119. Roper SN, Mena I, King WA, Schweitzer J, Garrett K, Mehringer $\mathrm{CM}$, et al. An analysis of cerebral blood flow in acute closed-head injury using technetium-99m-HMPAO SPECT and computed tomography. J Nucl Med 32:1684-1687, 1991.

120. Gray BG, Ichise M, Chung DG, Kirsh JC, Franks W. Technetium-99m-HMPAO SPECT in the evaluation of patients with a remote history of traumatic brain injury: a comparison with x-ray computed tomography. J Nucl Med 33:52-58, 1992.

121. Masdeu JC, Van Heertum RL, Kleiman A, Anselmi G, Kissane $\mathrm{K}$, Horng J, et al. Early single-photon emission computed tomography in mild head trauma. A controlled study. J Neuroimaging 4:177-181, 1994. 
122. Newton MR, Greenwood RJ, Britton KE, Charlesworth M, Nimmon CC, Carroll MJ, et al. A study comparing SPECT with CT and MRI after closed head injury. J Neurol Neurosurg Psychiatry 55:92-94, 1992.

123. Bonne O, Gilboa A, Louzoun Y, Kempf-Sherf O, Katz M, Fishman Y, et al. Cerebral blood flow in chronic symptomatic mild traumatic brain injury. Psychiatry Res 124:141-152, 2003.

124. Stamatakis EA, Wilson JT, Hadley DM, Wyper DJ. SPECT imaging in head injury interpreted with statistical parametric mapping. J Nucl Med 43:476-483, 2002.

125. Jacobs A, Put E, Ingels M, Put T, Bossuyt A. One-year follow-up of technetium-99m-HMPAO SPECT in mild head injury. $J$ Nucl Med 37:1605-1609, 1996.

126. Baulieu F, Fournier P, Baulieu JL, Dalonneau M, Chiaroni P, Eder V, et al. Technetium-99m ECD single photon emission computed tomography in brain trauma: comparison of early scintigraphic findings with long-term neuropsychological outcome. J Neuroimaging 11:112-120, 2001.

127. Oder W, Goldenberg G, Spatt J, Podreka I, Binder H, Deecke L. Behavioural and psychosocial sequelae of severe closed head injury and regional cerebral blood flow: a SPECT study. J Neurol Neurosurg Psychiatry 55:475-480, 1992.

128. Goldenberg G, Oder W, Spatt J, Podreka I. Cerebral correlates of disturbed executive function and memory in survivors of severe closed head injury: a SPECT study. J Neurol Neurosurg Psychiatry 55:362-368, 1992.

129. Radanov BP, Bicik I, Dvorak J, Antinnes J, von Schulthess GK, Buck A. Relation between neuropsychological and neuroimaging findings in patients with late whiplash syndrome. J Neurol Neurosurg Psychiatry 66:485-489, 1999.

130. Mitchener A, Wyper DJ, Patterson J, Hadley DM, Wilson JT, Scott LC, et al. SPECT, CT, and MRI in head injury: acute abnormalities followed up at six months. J Neurol Neurosurg Psychiatry 62:633-636, 1997.

131. Ichise M, Chung DG, Wang P, Wortzman G, Gray BG, Franks W. Technetium-99m-HMPAO SPECT, CT and MRI in the evaluation of patients with chronic traumatic brain injury: a correlation with neuropsychological performance. J Nucl Med 35:217-226, 1994.

132. Alavi A. Functional and anatomic studies of head injury. $J$ Neuropsychiatry Clin Neurosci 1:S45-S50, 1989.

133. Langfitt TW, Obrist WD, Alavi A, Grossman RI, Zimmerman R, Jaggi $\mathrm{J}$, et al. Computerized tomography, magnetic resonance imaging, and positron emission tomography in the study of brain trauma. Preliminary observations. J Neurosurg 64:760-767, 1986.

134. Humayun MS, Presty SK, Lafrance ND, Holcomb HH, Loats H, Long DM, et al. Local cerebral glucose abnormalities in mild closed head injured patients with cognitive impairments. Nucl Med Commun 10:335-344, 1989.

135. Rao N, Turski PA, Polcyn RE, Nickels RJ, Matthews CG, Flynn MM. 18F positron emission computed tomography in closed head injury. Arch Phys Med Rehabil 65:780-785, 1984.

136. Gross H, Kling A, Henry G, Herndon C, Lavretsky H. Local cerebral glucose metabolism in patients with long-term behavioral and cognitive deficits following mild traumatic brain injury. J Neuropsychiatry Clin Neurosci 8:324-334, 1996.

137. Ruff RM, Crouch JA, Troster AI, Marshall LF, Buchsbaum MS,
Lottenberg S, et al. Selected cases of poor outcome following a minor brain trauma: comparing neuropsychological and positron emission tomography assessment. Brain Inj 8:297-308, 1994.

138. Bergsneider M, Hovda DA, Lee SM, Kelly DF, McArthur DL, Vespa PM, et al. Dissociation of cerebral glucose metabolism and level of consciousness during the period of metabolic depression following human traumatic brain injury. J Neurotrauma 17:389401, 2000.

139. Bergsneider M, Hovda DA, McArthur DL, Etchepare M, Huang SC, Sehati N, et al. Metabolic recovery following human traumatic brain injury based on FDG-PET: time course and relationship to neurological disability. J Head Trauma Rehab 16:135$148,2001$.

140. Hatton J. Pharmacological treatment of traumatic brain injury: a review of agents in development. CNS Drugs 15:553-581, 2001.

141. Gentile NT, McIntosh TK. Antagonists of excitatory amino acids and endogenous opioid peptides in the treatment of experimental central nervous system injury. Ann Emerg Med 22:1028-1034, 1993.

142. Keynes RG, Garthwaite J. Nitric oxide and its role in ischaemic brain injury. Curr Mol Med 4:179-191, 2004.

143. Leker RR, Shohami E. Cerebral ischemia and trauma-different etiologies yet similar mechanisms: neuroprotective opportunities. Brain Res Brain Res Rev 39:55-73, 2002.

144. Morganti-Kossmann MC, Rancan M, Stahel PF, Kossmann T. Inflammatory response in acute traumatic brain injury: a doubleedged sword. Curr Opin Crit Care 8:101-105, 2002.

145. Zink BJ. Traumatic brain injury. Emerg Med Clin North Am 14:115-150, 1996.

146. Faden AI, O'Leary DM, Fan L, Bao W, Mullins PG, Movsesyan VA. Selective blockade of the mGluR1 receptor reduces traumatic neuronal injury in vitro and improves outcome after brain trauma. Exp Neurol 167:435-444, 2001.

147. Movsesyan VA, O'Leary DM, Fan L, Bao W, Mullins PG, Knoblach SM, et al. mGluR5 antagonists 2-methyl-6-(phenylethynyl)-pyridine and (E)-2-methyl-6-(2-phenylethenyl)-pyridine reduce traumatic neuronal injury in vitro and in vivo by antagonizing N-methyl-D-aspartate receptors. J Pharmacol Exp Ther 296:41-47, 2001.

148. Steiner LA, Coles JP, Johnston AJ, Czosnyka M, Fryer TD, Smielewski P, et al. Responses of posttraumatic pericontusional cerebral blood flow and blood volume to an increase in cerebral perfusion pressure. J Cereb Blood Flow Metab 23:1371-1377, 2003.

149. Richards HK, Simac S, Piechnik S, Pickard JD. Uncoupling of cerebral blood flow and metabolism after cerebral contusion in the rat. J Cereb Blood Flow Metab 21:779-781, 2001.

150. Yamaki T, Imahori Y, Ohmori Y, Yoshino E, Hohri T, Ebisu T, et al. Cerebral hemodynamics and metabolism of severe diffuse brain injury measured by PET. J Nucl Med 37:1166-1170, 1996.

151. Shi XY, Tang ZQ, Xiong B, Bao JX, Sun D, Zhang YQ, et al. Cerebral perfusion SPECT imaging for assessment of the effect of hyperbaric oxygen therapy on patients with postbrain injury neural status. Chin J Traumatol 6:346-349, 2003.

152. Coles JP, Minhas PS, Fryer TD, Smielewski P, Aigbirihio F, Donovan $\mathrm{T}$, et al. Effect of hyperventilation on cerebral blood flow in traumatic head injury: clinical relevance and monitoring correlates. Crit Care Med 30:1950-1959, 2002. 